\title{
Anxiety Levels of Footballers in Regional Amateur and Professional Leagues During Pandemic Process
}

\section{Fatih Evli, Osman Gidik, Emrah Cerit}

Hitit University, Faculty of Sport Sciences, Corum, Turkey

Study Area: Corum, Turkey

Coordinates: $40^{\circ} 33^{\prime} \mathrm{oo}$ ? N $34^{\circ} 57^{\prime} 14$ ? E

Key words: Stateanxiety, Covid-19, Trait anxiety, Football, Pandemic

\section{Introduction:}

Sports can be described as a social institution that has multifaceted and significant effects on many issues such as economy, politics, education and international relations. In our era, the sport has gained a very effective dimension and been universal depending on these characteristics (Yetim, 200o). Football occupies a special place within the concept of universalised sports both in terms of its economy and the interest it receives by societies. Football economy, which reveals its economic value as a result of globalisation, is referred to in the literature with different concepts as football industry enterprise, football business, commercial football and industrial football. The game of football, which is no longer an entertainment tool for leisure time, has today been transformed into the final goods and services through production factors and has become a product that is marketed to the audience and/or fans on a global basis. (Gungor, 2014). Besides its economic dimension, there are physiological and psychological dimensions specific to athletes in football, as well as in other sports branches. The

\section{Abstract}

This study aims to examine the anxiety levels of athletes playing football in different leagues in terms of marital status, the league they play in, communication between teammates, eating habits, hygiene habits, approach to people and training program variables. The study was carried out on 447 regional amateur league football players and 173 professional league football players in the 2019-2020 football season when the Covid-19 outbreak was as intense in our country as the whole world. In the study, the StateTrait Anxiety Inventory to measure participants' state and trait anxiety levels were used as a data collection tool. A significant difference was found in the state anxiety of participants according to the variable of the league they played. A significant difference was observed in trait anxiety levels regarding communication with teammates. It was observed that there was a significant difference in state anxiety levels in the dietary habits variable. Regarding cleaning habits, there was a significant difference in both state and trait anxiety levels. A significant difference was found in both the state and trait anxiety levels of the participants about their attitudes towards people. A significant difference was observed in the state anxiety of the participants who were given a training program by the club they played in. .

physiological well-being of athletes is also related to their psychology. One of the concepts that affect athletes psychologically is their anxiety levels.

Anxiety is expressed by (Oncul, 2000) as a state of excitement mixed with a feeling of insecurity and an upsetting, devastating state of waiting for the future. The person with a sense of anxiety experiences anxiousness is constantly on the lookout and feel like something bad is going to happen at any moment (Nar, 2005). Anxiety, which is a process of internal and external events that develop unexpectedly and uncontrollably, is handled in two as state and trait anxiety. State anxiety is the fear experienced by the individual due to the stressful situations the person is in as well as an indicator of the individual's feelings such as tension and restlessness. Trait anxiety is dependence of the individual on his anxiety experience (Hacicaferoglu et al., 2015).

While state anxiety is defined as perceiving certain conditions as threatening, trait anxiety means that the 
individual perceives every environment as stressful in stressful. Therefore, when the literature on stress and anxiety is examined, it can be said that state anxiety plays a triggering role in coping mechanisms when faced with stressful events; whereas trait anxiety is associated with insufficient coping mechanisms. The findings of some studies examining the connection between anxiety and depression show that state anxiety is a temporary condition and is affected by the specific conditions of the environment; trait anxiety, on the other hand, is more closely related to personality traits such as the perception of stress and depression as a predisposition (Hovardaoglu, 1994). In athletes, high or low anxiety negatively affects the athlete's performance. The level of anxiety should be proportioned by those who take care of athletes in a way that will develop positive performance in the athlete. This is an important factor in the creation of success (Donmez, 2013).

In this study, we tried to know how the Covid-19 pandemic, which negatively affected the whole world and Turkey in all areas, affected the anxiety levels of participants playing football in different leagues. It can be stated that the pandemic negatively affects the physical and psychological conditions of football players as well as the economic situation of the clubs.

The study sought answers to the following questions:

1. Is there a significant relationship between the nutrition habits of the participants and their anxiety levels during the pandemic process?

2. Is there a significant relationship between the league the participants played in and their anxiety levels?

3. Is there a significant relationship between the marital status of the participants and their anxiety levels?

4. Is there a significant relationship between the cleaning habits of the participants and their anxiety levels?

5. Is there a significant relationship between the training status of the participants and their anxiety levels?

6. Is there a significant relationship between the participants' approach to people and their anxiety levels?

7. Is there a significant relationship between the communication between the participants' teammates and their anxiety levels?

\section{Methodology:}

The study was carried out to examine the anxiety levels of individuals playing football in regional amateur and professional leagues in Turkey during the pandemic process, which has negative impacts in our country as well as the world. In the study, it was intended to reveal the status of the participants and the general survey model was used.

The study included 447 players who actively played football in the Regional Amateur Leagues and 173 players who actively play football in professional leagues (super league, istleague, and league, 3 rd league).

To determine the state and anxiety levels of the participants, the Trait and State Anxiety Inventory, which was developed by Spielberger et al. (1983) and whose reliability and validity studies were conducted and translated into Turkish by (Oner \& Le Compte, 1983), was used.

The necessary Ethics Committee Approval has been obtained within the scope of the research. Due to the conditions in the pandemic process, remote access was provided to the participants the internet. Before applying the scales, participants were informed that the study was carried out voluntarily.

In the analysis of the data obtained in the study, it was first examined whether the data showed normal distribution or not. In the analysis of the data determined to show normal distribution, the T-Test was applied to determine whether there is a significant difference between the two independent variables. The level of significance in the study was accepted as p?.05.

\section{Results :}

\section{Results are summarized in Table 1 \& 2.}

As per Table-1, no significant difference was found regarding the marital status variable in the data obtained regarding the state anxiety of the participants.

Table-1: Examining the state anxiety levels of the participants in terms of different variables.

\begin{tabular}{|c|c|c|c|c|}
\hline Variables & $\mathrm{N}$ & $\mathrm{X}$ & SS & \\
\hline \multicolumn{5}{|l|}{ Marital Status } \\
\hline Married & 151 & 2.1291 & 0.28852 & $\mathrm{Sd}=618 ; \mathrm{T}=0.258$ \\
\hline Single & 469 & 2.1225 & 0.27023 & $P>0.796$ \\
\hline \multicolumn{5}{|c|}{ The League You Play In } \\
\hline Reg. Amateur League & 447 & 2.1082 & 0.25674 & $\mathrm{Sd}=266.210 ; \mathrm{T}=-2.139$ \\
\hline Professional Leagues & 173 & 2.1653 & 0.31310 & $\mathrm{P}<0.033$ \\
\hline \multicolumn{5}{|c|}{ The Effect of Covid-19 Outbreak on Commu. Between Teammates } \\
\hline Negatively impacted & 446 & 2.1343 & 0.29431 & $\mathrm{Sd}=430.303 ; \mathrm{T}=1.696$ \\
\hline Not effected & 174 & 2.0980 & 0.21446 & $\mathrm{P}>0.091$ \\
\hline \multicolumn{5}{|c|}{ The Effect of Covid-19 Outbreak on Eating Habits } \\
\hline Yes & 413 & 2.1408 & 0.29870 & $\mathrm{Sd}=542.398 ; \mathrm{T}=2.382$ \\
\hline No & 207 & 2.0908 & 0.21545 & $\mathrm{P}<0.018$ \\
\hline \multicolumn{5}{|c|}{ The Effect of Covid-19 Outbreak on Cleaning Habits } \\
\hline Yes & 543 & 2.1336 & 0.27656 & $\mathrm{Sd}=618 ; \mathrm{T}=\mathbf{2 . 2 9 5}$ \\
\hline No & 77 & 2.0571 & 0.25180 & $\mathrm{P}<0.022$ \\
\hline \multicolumn{5}{|c|}{ My Approach to People Changed After Covid-19 } \\
\hline Yes & 566 & 2.1318 & 0.28038 & Sd-77.667; T=3.140 \\
\hline No & 54 & 2.0435 & 0.18760 & $\mathrm{P}<0.002$ \\
\hline \multicolumn{5}{|c|}{ Have You Been Given a Training Program by Your Club } \\
\hline Yes & 284 & 2.1505 & 0.27171 & $\mathrm{Sd}=618 ; \mathrm{T}=2.209$ \\
\hline No & 336 & 2.1018 & 0.27540 & $\mathrm{P}<0.028$ \\
\hline
\end{tabular}

When the results were analysed according to the leaguevariable they play, a significant result was obtained in favour of the participants who played in professional leagues. When the effect of the pandemic on communication with their teammates was examined, it was seen that the state anxiety levels of the participants who stated that they were negatively impacted were found to be high, however, no significant results were found among the participants who stated that they were not affected. There is a significant difference in favour of those who stated that there was a change both in their nutritional and cleaning 
habits during the pandemic process. A significant difference was found between the participants in the variable related to the approach towards people in the pandemic. A significant difference was observed between the participants in the variable of whether a training program was provided by the clubs where the participants played in. Participants who were given a training program by their clubs are more likely to have higher state anxiety.

Table-1: Analysis of the trait anxiety levels of the participants in terms of different variables.

\begin{tabular}{lllll}
\hline Variables & $\mathrm{N}$ & $\mathrm{X}$ & $\mathrm{SS}$ & \\
\hline Marital Status & & & \\
Married & 151 & 2.3000 & .31246 & $\mathrm{Sd}=618 ; \mathrm{T}=1.030$ \\
Single & 469 & 2.2729 & .27023 & $\mathrm{P}>0.304$ \\
The League You Play In & & & \\
Reg. Amateur League & 447 & 2.2708 & 0.26539 & $\mathrm{Sd}=618 ; \mathrm{T}=-1.241$ \\
Professional Leagues & 173 & 2.3020 & 0.31780 & $\mathrm{P}<0.234$ \\
The Effect of Covid-19 & Outbreak on Commu. Between Teammates \\
Negatively impacted & 446 & 2.3015 & .29703 & $\mathrm{Sd}=411.013 ; \mathrm{T}=3.522$ \\
Not effected & 174 & 2.2233 & .22654 & $\mathrm{P}>0.000$ \\
The Effect of Covid-19 & Outbreak on Eating Habits \\
Yes & 413 & 2.2952 & .28908 & $\mathrm{Sd}=618 ; \mathrm{T}=1.962$ \\
No & 207 & 2.2483 & .26229 & $\mathrm{P}<0.050$ \\
The Effect of Covid-19 Outbreak on Cleaning & Habits \\
Yes & 543 & 2.2931 & .28452 & $\mathrm{Sd}=618 ; \mathrm{T}=3.218$ \\
No & 77 & 2.1838 & .23570 & $\mathrm{P}<0.001$ \\
My Approach to People Changed After Covid-19 & \\
Yes & 566 & 2.2870 & .28321 & $\mathrm{Sd}-618 ; \mathrm{T}=2.157$ \\
No & 54 & 2.2009 & .24658 & $\mathrm{P}<0.031$ \\
Have You Been Given a Training Program by Your Club \\
Yes & 284 & 2.2891 & .28244 & $\mathrm{Sd}=618 ; \mathrm{T}=.779$ \\
No & 336 & 2.2714 & .28009 & $\mathrm{P}<0.436$ \\
\hline
\end{tabular}

In Table-2 no difference was found regarding the marital status variable in the data obtained regarding the trait anxiety of the participants. When the results were examined according to the league variable they played, no significant results were found between the participants. When the effect of the pandemic on the communication with their teammate was examined, it was seen that the participants who stated that they were negatively affected had high levels of trait anxiety and a significant difference was found between the participants who stated that they were not affected. While there was no significant difference in the eating habits of the participants regarding their dietary and cleaning habits during the pandemic process, there was a significant difference in cleaning habits among the participants, in favour of those who stated that their cleaning habits have changed. A significant difference was found between the participants in the variable related to the approach to people in the pandemic. There was no significant difference between the participants in the variable of whether a training program was provided by the clubs where the participants played football.

\section{Discussion}

In the study, the state and trait anxiety levels of amateur and professional football players, who actively play football in the 2019-2020 season related to the pandemic process were examined through various variables. The participants' anxiety levels related to their marital status, the league they play in, relationship with friends, eating and hygiene habits, approach to people and training programs were tried to be revealed. During the pandemic process, it is seen that the whole world has entered into a difficult period in many areas, especially in terms of social, economic and psychological aspects, due to the process. There's a strong link between the psychological state of the individual and their psychological health. The concept expressed in medicine as neuroimmune modulation is considered an important definition. The concept focuses on the effect of an individual's mood on their immune system. It is stated that all positive thoughts and behaviours are as effective as vitamins, minerals and antioxidants (Aslan, 2020). Considering that psychological well-being also affects physical health, it is important to reveal the status of individuals who play football and play football for a living. When the state and trait anxiety levels of the participants were examined according to the marital status variable, no significant difference was found (Tables 1 \& 2). Çiftçi \& Demir (2020) conducted on professional football players examined the fear and anxiety levels of the participants and found no significant difference between married and single participants in the marital status variable. Similarly, Yurur (2011) examined emotional exhaustion levels, which is a psychological concept similar to anxiety, no significant relationship was found between marital status and the concept. When the research results and similar studies are examined, it can be stated that there is no significant relationship between marital status and anxiety.

When the anxiety levels of the participants were examined according to the variable of the league they played in, it was concluded that their state anxiety levels were higher in professional players (Table-1). It is concluded that there is a significant difference between amateur football players and professional football players. Examining the state anxiety levels of football players Arisoy et al. (2020) stated that the state anxiety levels of the participants regarding the return to football were high Tingaz (2020) stated that the uncertainty that elite athletes have in connection with the pandemic is concerned about the future sports environment and their athletic performance. Based on these studies, which are similar to the results of the research, it is concluded that high.level athletes have high state anxiety due to the uncertainty in the pandemic environment. Itcanbestated that thisuncertainty increases the anxiety levels of these athletes, who perform sports as a profession for reasons such as earning money and stayinginshape.

During the pandemic, physical distance is one of the most needed practices as a precaution to prevent the spread of the disease. It can be said that this situation physically distances people from each other. Physical 
distancing can also bring along communication problems. When the participants were asked about their communication with their teammates during the pandemic, no significant difference was found in terms of state anxiety levels (Table ${ }^{-1}$ ), but a significant difference was found in terms of trait anxiety levels (Table-2). However, a significant difference was found between those who stated that their approach to people changed, in terms of both state and trait anxiety levels (Tables $1^{-}$ 2).A study of (Esidir \& Bak, 2020) states that the gathering of individuals and various activities in international environments will decrease the elimination of the virus. In the longer term, it states that it will change both the communication between countries and interpersonal communication.

It was concluded that there was a significant difference in terms of both state and trait anxiety levels regarding the hygiene habits variable of the participants (Tables 1-2). In a study conducted in Turkey in general Ugurlu et al. (2020) stated that the frequency of hand sanitising/washing of $89.4 \%$ of individuals has increased during the Covid-19 outbreak. Especially during the pandemic, the importance of hand sanitising has increased. In Indonesia, it has been observed that regular hand cleaning is not observed at a rate of $50.2 \%$ and continuous information is provided about hand cleaning in digital and written media outlets (Purnama \& Susanna, 2020). In a study conducted on people living in various regions of Poland, the frequency of handwashing before and during the pandemic was investigated. As a result of the research, it is stated that the frequency of handwashing of the participants increased significantly during the pandemic period (Glabska et al., 2020). The results obtained in the study are similar to other studies. It can be stated that during the pandemic process, the cleaning habits of the individuals have changed positively with the concern of protection from the disease.

The period of restraint in many countries, boredom and stress can cause athletes to lose their routine everyday habits. Overeating is a new condition that can lead them to adopt poor eating habits, especially foods rich in sugar and fat. Therefore, nutrition education for athletes is a situation that should be seriously evaluated by experts (Yousfi et al., 2020). Akyol \& Celik (2020) states that the negativity in the eating habits of those who do sports 6-7 days a week is lower than those who do less exercise. In another study, it is stated that during the restriction period, individuals consume more fat and carbohydrate-rich foods due to stress and do not follow their diets (Garl poglu \& Bozar, 2020). Here, a significant difference was found between the participants in terms of state anxiety in the nutrition variable (Table-1). During the pandemic, the eating habits of the individuals change depending on the psychological factors. The findings can be interpreted as pandemic negatively affecting eating habits.
During the restriction period of the pandemic, changes and disruptions have also emerged in the regular training plans of athletes. It can be stated that these disruptions in the training programs of individuals who do high-level sports and uncertainty about the pandemic also negatively affect them psychologically. In the study, a significant difference in situation anxiety was found between the participants who were given a training program by their clubs and who were not. In the study of (Olmez et al., 2020) on elite taekwondo athletes, the participants were asked about the positive and negative aspects of home training, it was concluded that $42.86 \%$ had problems with equipment and support. In the same study, the concepts of loading and adaption were stated as the dominant problem. It is stated that the participants are negatively affected by technical training, not being able to compete and low intensity of the training. In a study by Demirtas \& Ciplak (2020) conducted on the wrestling national team, it was seen that participants were also concerned about the lack of training and especially technical training and uncertainty. In our study, a significant difference was found in terms of state anxiety of the athletes who had been given training program. It is thought that this difference in state anxiety can be explained by topics such as how athletes will apply their training program, training location, technical deficiency, lack of partners, lack of competition.

A significant difference was found in the state anxiety of the participants according to the variable of the league they play in. A significant difference was observed in trait anxiety levels regarding communication with teammates. It was observed that there was a significant difference in state anxiety levels in the dietary habits variable. Regarding cleaning habits, a significant difference was observed in both state and trait anxiety levels. A significant difference was found in both the state and trait anxiety levels of the participants about their approach towards people. A significant difference was observed in the state anxiety of the participants who were given a training program by the club they played.

As a result, the pandemic process has negatively affected the whole world in economic, social, psychological and physiological aspects and continues to affect it. It is observed that cases of severe disease, deaths and the rate of spread of the pandemic negatively affect people in all aspects. Sports organisations and athletes, like all areas, have been closely affected by this difficult process. It can be stated that situations such as the cancellation of sports organisations and postponement of leagues negatively affect the stakeholders in the sports industry both economically and psychologically.

\section{References:}

Akyol, P. \& Celik, A. (2020): Investigation of the dietary habits of paramedic students during the Covid-19 outbreak. Electr. 


\section{ORIGINAL ARTICLE}

Turk. Stud., 15(4).

Andreato, L. V., Coimbra, D. R., \& Andrade, A. (2020):challenges to athletes during the home confinement caused by the covid19 pandemic. Strength Condition. I.

Arısoy, A., Pepe, O. \& Karaoglu, B. (2020): Determination of the relationship between the state anxiety levels of football players and their psychological performance before returning to football in the process of Covid-19. Yalvac Acad. J.. 5(1):55-63.

Aslan, R. (2020): Covid-19, pandemics and epidemics from history to the present, Ayrınti L., 8(85).

Bak G . Esdr OV 2020 The communication dimension of the Covid 1ovirusasanewmilestonein theworld

Ciftci, F. \& Demir, A. (2020): Examining the fear and anxiety levels of Turkish professional footballers in the covid-19 pandemic. L. Sports Recreat. Res., 2(S-1):26-38.

Demirtas, Ö. \& Ciplak, A. (2020): The effects of the pandemic process on the wrestling national team athletes preparing for international competitions. J. Sports Recreat. Res., 2(S-1):3952.

Donmez, K.H. (2020): Investigation of state anxiety and trait anxiety levels of athletes participating in inter-university basketball competitions held in Samsun province, I. Acad. Soc. Sci. Stud.

Garipoglu, G. \& Bozar, N. (2020): Changes in the eating habits of individuals in social isolation in the Covid-19 outbreak. PearsonJ. Soc. Sci. Human., 6(6):100-113.

Gungor, A. (2014): Economic dimension of the European football market and financial performance analysis in European football clubs: Istanbul Gelisim Univers. L. Soc. Sci., 1(2):133160.

Hacicaferoglu, S., Hacicaferoglu, B. \& Secer M. (2015): Examining the pre-competition anxiety levels of the athletes participating in the folk dance branch in terms of some variables.Int.J. Sports Cul. Sci., 3(S-4):288-297.
Ambient Science, 2020: Vol. 07(Sp1); 81-85 DOI:10.21276/ambi.2020.07.sp1.oa09

Hovardaoglu, S. (1994): Prediction of stress symptoms and trait and state anxiety. Kriz J., 5(2):127-134.

Nar, E. (2005): Understand Me. 3rd Edition Pub. by: Babiali Cultural Publishing.

Olmez, C., Aydemir, B., Sar, H. \& Oztas, M. (2020): Investigation of the performance status of elite taekwondo athletes under covid-19 conditions: a mixed study. Clin. Sport Sci. Turkey. $12(2)$.

Oncul, R. (200o): Dictionary of Education and Educational Sciences. Pub. by: M.E.B. Publications.

Purnama, S. G. \& Susanna, D. (2020): Hygiene and sanitation challenge for covid-19 prevention in indonesia. Kesmas Nat. Pub. Health I., 15(2).

Tingaz, E. O. (2020): The psychological impact of the covid ${ }^{-19}$ pandemic on elite athletes, management strategies and post-pandemic performance expectations: A SemiStructured Interview Study. Int. J. Edu. Res. Inno., (15): $73^{-}$ 81.

Ugurlu, Y. K. U. K., Durgun, H., Nemutlu, E. \& Kurd O. (2020): Assessment of Turkish community's social handwashing knowledge and attitude during the COVID-19 pandemic. $L$. Contemp. Med., 10:1-8.

Yetim, A. (2000): Social view of sports. Gazi J. Phys. Edu. Sport Sci., $5^{(1)}: 63^{-} 7^{2}$.

Yousfi, N., Bragazzi, N. L., Briki, W., Zmijewski, P., Chamari, K. (2020): The COVID-19 pandemic: how to maintain a healthy immune system during the lockdown?a multidisciplinary approach with special focus on athletes. Biol. Sport, 37(3):211.

Yurur, S. (2011): The role of learned resourcefulness, seniority ad marital status in emotional exhaustion: an analysis in the context of conservation theory. Atatürk Univers. J. Econ. Admin. Sci., 25(1):107-126. 